\title{
Complete mitochondrial DNA sequence of oyster Crassostrea hongkongensis-a case of "Tandem duplication-random loss" for genome rearrangement in Crassostrea?
}

\author{
Ziniu $\mathrm{Yu}^{1}$, Zhengpeng $\mathrm{Wei}^{2}$, Xiaoyu Kong ${ }^{* 1}$ and Wei Shi ${ }^{2}$
}

Address: ${ }^{1}$ Laboratory of Marine Bio-resource Sustainable Utilization, Laboratory of Applied Marine Biology; South China Sea Institute of Oceanology, Chinese Academy of Sciences, 164 West Xingang Road, Guangzhou 510301, PR China and 2Laboratory of Mariculture Research, Ocean University of China, 5 Yushan Road, Qingdao 266003, PR China

Email: Ziniu Yu - carlzyu@scsio.ac.cn; Zhengpeng Wei - weizhengpeng1234@yahoo.com.cn; Xiaoyu Kong* - xykong@scsio.ac.cn; Wei Shi - sddxsw@hotmail.com

* Corresponding author

Published: II October 2008

BMC Genomics 2008, 9:477 doi:10.1/86/|47|-2/64-9-477
Received: 18 February 2008

Accepted: II October 2008

This article is available from: http://www.biomedcentral.com/I47I-2I64/9/477

(c) 2008 Yu et al; licensee BioMed Central Ltd.

This is an Open Access article distributed under the terms of the Creative Commons Attribution License (http://creativecommons.org/licenses/by/2.0), which permits unrestricted use, distribution, and reproduction in any medium, provided the original work is properly cited.

\begin{abstract}
Background: Mitochondrial DNA sequences are extensively used as genetic markers not only for studies of population or ecological genetics, but also for phylogenetic and evolutionary analyses. Complete mt-sequences can reveal information about gene order and its variation, as well as gene and genome evolution when sequences from multiple phyla are compared. Mitochondrial gene order is highly variable among mollusks, with bivalves exhibiting the most variability. Of the $4 \mathrm{I}$ complete $\mathrm{mt}$ genomes sequenced so far, 12 are from bivalves. We determined, in the current study, the complete mitochondrial DNA sequence of Crassostrea hongkongensis. We present here an analysis of features of its gene content and genome organization in comparison with two other Crassostrea species to assess the variation within bivalves and among main groups of mollusks.
\end{abstract}

Results: The complete mitochondrial genome of $C$. hongkongensis was determined using long PCR and a primer walking sequencing strategy with genus-specific primers. The genome is 16,475 bp in length and contains 12 protein-coding genes (the atp8 gene is missing, as in most bivalves), 22 transfer tRNA genes (including a suppressor tRNA gene), and 2 ribosomal RNA genes, all of which appear to be transcribed from the same strand. A striking finding of this study is that a DNA segment containing four tRNA genes (trnk $I$, $\operatorname{trn} C, \operatorname{trn} Q I$ and $\operatorname{trnN}$ ) and two duplicated or split rRNA gene ( $r r n L 5$ ' and $r r n S$ ) are absent from the genome, when compared with that of two other extant Crassostrea species, which is very likely a consequence of loss of a single genomic region present in ancestor of $C$. hongkongensis. It indicates this region seem to be a "hot spot" of genomic rearrangements over the Crassostrea mt-genomes. The arrangement of protein-coding genes in $C$. hongkongensis is identical to that of Crassostrea gigas and Crassostrea virginica, but higher amino acid sequence identities are shared between $C$. hongkongensis and $C$. gigas than between other pairs. There exists significant codon bias, favoring codons ending in $A$ or $T$ and against those ending with C. Pair analysis of genome rearrangements showed that the rearrangement distance is great between $C$. gigas- $C$. hongkongensis and $C$. virginica, indicating a high degree of rearrangements within Crassostrea. The determination of complete mt-genome of $C$. hongkongensis has yielded useful insight into features of gene order, variation, and evolution of Crassostrea and bivalve mt-genomes. 


\begin{abstract}
Conclusion: The $\mathrm{mt}$-genome of $C$. hongkongensis shares some similarity with, and interesting differences to, other Crassostrea species and bivalves. The absence of $\operatorname{trn} C$ and $\operatorname{trn} N$ genes and duplicated or split rRNA genes from the $C$. hongkongensis genome is a completely novel feature not previously reported in Crassostrea species. The phenomenon is likely due to the loss of a segment that is present in other Crassostrea species and was present in ancestor of $C$. hongkongensis, thus a case of "tandem duplication-random loss (TDRL)". The mt-genome and new feature presented here reveal and underline the high level variation of gene order and gene content in Crassostrea and bivalves, inspiring more research to gain understanding to mechanisms underlying gene and genome evolution in bivalves and mollusks.
\end{abstract}

\section{Background}

As an organellar genome, animal mitochondrial DNA is typically a circular molecule of $15-20 \mathrm{~kb}$, usually encoding 13 proteins, 22 transfer RNAs, and 2 ribosomal RNAs [1]. Thanks to its maternal inheritance, rapid evolutionary rate, and lack of recombination, fragments of mitochondrial DNA have been extensively used for studies of genetic structure, phylogenetics, and phylogeography at various taxonomic levels. Since studying complete $\mathrm{mt}$ sequences can uncover more information about gene order, rearrangements, and other variation at the genome level for all phyla, there have been significant increases in the number of complete mitochondrial sequences available in recent years [2-7]. It is known that mitochondrial gene order and its variation can be very useful for inferring evolutionary relationships [8]. Reportedly, molluscan species show an extraordinary amount of variation in gene arrangement, in contrast to the more limited gene rearrangement in many species of Arthropoda [3,4,6].

Of the 41 complete mollusk mt genomes available in GenBank, 12 of which are from bivalves, including Mytilus edulis, Mytilus trossulus, Mytilus galloprovincialis, Venerupis philippinarum, Lampsilis ornata etc., as well as two from oyster species. Oysters are distributed worldwide and are a species-rich bivalve group. Mitochondrial genomes of two oyster species, C. gigas and C. virginica, are available recently [5]. In comparing the mt-DNA of these two species, there is evidence of extensive genomic rearrangements and several duplications; mitochondrial genome information from additional species, therefore, would shed light on our relatively limited understanding of oyster evolutionary relationships.

C. hongkongensis (known as C. rivularis, previously) is primarily found in waters along the coast of the South China Sea [9]. With an annual landing of around 1.0 million metric tons, oyster farming of $C$. hongkongensis has been supporting one of the largest marine aquaculture industries in this area, marketing its products primarily to Hong Kong, Macau, Taiwan, and local markets as well. Populations were studied using different genetic markers, however, more polymorphic markers are needed for better and more detailed stock analysis [10-12]. With the process of urbanization and industrialization in some coastal regions, wild populations of this species have experienced some degree of decline. Meanwhile, the development of the oyster farming industry is driving resource management concerns and a desire for stock improvement. Stock enhancement is desired for stable and sustainable development of this industry. Interest in C. hongkongensis mitochondrial DNA has been increasing recently, partially due to the potential of mtDNA as a genetic marker for population analysis, stock management, and breeding programs. In this study, we determined the complete mitochondrial genome sequence of $C$. hongkongensis, in the hope of providing $\mathrm{mt}$ genome data for exploring possible mechanisms of gene rearrangements, addressing phylogenetic relationships among oysters and other molluscan species, as well as identifying more variable mtDNA regions for genetics studies and stock management of this important aquaculture resource.

\section{Results and discussion Genomic organization and structure}

The mitochondrial genome of $C$. hongkongensis is 16,475 bp in length (GenBank accession number EU266073), shorter than that of the other two oysters whose mtgenomes have been sequenced, C. gigas (18,224 bp) and C. virginica $(17,243 \mathrm{bp})$. However, the size of the C. hongkongesis mt-genome is certainly within the range of size of molluscan mtDNA genomes sequenced to date, i.e. from 13,670 bp in Biomphalaria glabrata to 32,115 bp in Placopecten magellanicus. The $C$. hongkongensis mtDNA contains 12 protein-coding genes (without atp8), 22 transfer tRNA genes (including a suppressor tRNA gene) and 2 ribosomal RNA genes (Fig. 1, 2 and Table 1), all apparently transcribed from the same strand, a common feature in marine bivalves.

The arrangement of protein-coding genes in C. hongkongensis is identical to that of $C$. gigas and C. virginica, in the order of cox1, cox3, cob, cox2, atp6, nad2, nad4, nad5, nad6, nad3, nad1 and nad4L (Fig. 2), with tRNA genes punctuating the order [5]. However, the location of some tRNA genes, ribosomal RNA genes and a major noncoding 
Table I: Features of Crassostrea hongkongensis mitochondrial genome

\begin{tabular}{|c|c|c|c|c|c|}
\hline Feature & Sequence location & Size & Start codon & Stop codon & Intergenic region§ \\
\hline $\operatorname{cox} I$ & $1-1620$ & 1620 & ATA & TAA & 143 \\
\hline$r r n L$ & $1764-2475$ & 712 & & & 96 \\
\hline $\operatorname{cox} 3$ & $2572-344 \mid$ & 870 & ATA & TAA & 0 \\
\hline trnl & $3442-3508$ & 67 & & & 0 \\
\hline $\operatorname{trn} T$ & $3509-3576$ & 68 & & & 21 \\
\hline $\operatorname{trn} E$ & $3598-3665$ & 68 & & & 7 \\
\hline$c o b$ & $3673-4878$ & 1206 & ATA & TAA & 8 \\
\hline $\operatorname{trn} D$ & $4987-5055$ & 69 & & & 1 \\
\hline $\operatorname{cox} 2$ & $5057-5758$ & 702 & ATG & TAG & 21 \\
\hline $\operatorname{trn} M I$ & $5780-5845$ & 66 & & & 0 \\
\hline $\operatorname{trnSI}$ & $5846-5917$ & 72 & & & 16 \\
\hline $\operatorname{trnL2}$ & $5934-6000$ & 67 & & & 67 \\
\hline $\operatorname{trn} M 2$ & $6068-6132$ & 65 & & & 7 \\
\hline $\operatorname{trnS2}$ & $6140-6207$ & 68 & & & 178 \\
\hline $\operatorname{trn} P$ & $6386-6454$ & 69 & & & 103 \\
\hline$r r n S$ & $6558-7505$ & 948 & & & 49 \\
\hline $\operatorname{trn} Y$ & $7555-7620$ & 66 & & & 5 \\
\hline atp6 & $7626-8309$ & 684 & ATG & TAG & 152 \\
\hline Sup & $8462-8527$ & 66 & & & 294 \\
\hline $\operatorname{trn} G$ & $8822-8891$ & 70 & & & 0 \\
\hline$M N R$ & 8892-9499 & 608 & & & 0 \\
\hline $\operatorname{trn} V$ & $9500-9572$ & 73 & & & 42 \\
\hline nad2 & $9615-10613$ & 999 & ATG & TAG & 34 \\
\hline $\operatorname{trn} R$ & $10648-107 \mid 4$ & 67 & & & 60 \\
\hline $\operatorname{trnH}$ & $10775-10839$ & 65 & & & -1 \\
\hline nad4 & $10839-12191$ & 1353 & ATA & TAG & 7 \\
\hline $\operatorname{trnK}$ & $12199-12273$ & 75 & & & 1 \\
\hline nad5 & $12275-13945$ & 1671 & ATG & TAA & 14 \\
\hline nad6 & |3960-14433 & 474 & ATG & TAA & 32 \\
\hline $\operatorname{trn} Q$ & $|4466-| 4534$ & 69 & & & 5 \\
\hline nad3 & $|4540-| 4890$ & 351 & ATG & TAG & 35 \\
\hline $\operatorname{trnLI}$ & |4926-|499| & 66 & & & 35 \\
\hline $\operatorname{trnF}$ & |5027-| 5094 & 68 & & & 20 \\
\hline $\operatorname{trn} A$ & $|5||5-15| 8 \mid$ & 67 & & & 5 \\
\hline nadl & $15187-16122$ & 936 & ATG & TAA & 3 \\
\hline nad4L & $16126-16405$ & 280 & ATG & $\mathrm{T}$ & 0 \\
\hline $\operatorname{trnW}$ & $16406-16474$ & 69 & & & 1 \\
\hline
\end{tabular}

§Intergenic region refer to noncoding bases between the feature on the same line and the feature on the line underneath, with a negative number indicating an overlap.

region (MNR) differ to a great extent among the three Crassostrea genomes (Fig. 2). The overall genomic organization of $C$. hongkongensis is more similar to that of $C$. gigas than to C. virginica, corresponding evidently to their closer genetic relationship. In contrast, in Mytilus congeners M. edulis, M. trossulus and M. galloprovincialis, not only are protein-coding genes arranged in the following identical order: cox1, atp6, nad4L, nad5, nad6, cob, cox2, nad1, nad4, cox3, nad2 and nad3; but also the order of tRNAs, ribosomal RNA, and control region are almost the same. In other words, gene arrangement is highly conserved among Mytilus species.

The major mt-genomic region significantly different among the three Crassostrea genomes is that between $c o b$ and nad2 (Fig. 2), with other regions being almost identi- cal. In this variable region, C. gigas and C. virginica have a segment (between rrnS and trnY) that is completely absent in C. hongkongensis. This is a totally striking finding regarding mt genome structure of Crassostrea. The segment contains split $r r n L 5 '$, duplicated $r r n S$ and four tRNA genes in C. gigas, and split rrnL5' and seven tRNA genes in C. virginica, respectively. Additionally, there is obvious variation of gene order in the C. virginica when compared with the other two species: MNR is translocated between cox 2 and $r r n S$, and some tRNA genes are rearranged. Therefore, this section seems to be an obvious "hot spot" of rearrangement in Crassostrea mt genome.

The relationship of genome length in the 3 Crassostrea species may be a reflection of the segment's loss: although $C$. gigas is more closely-related to C. hongkongensis than to $C$. 


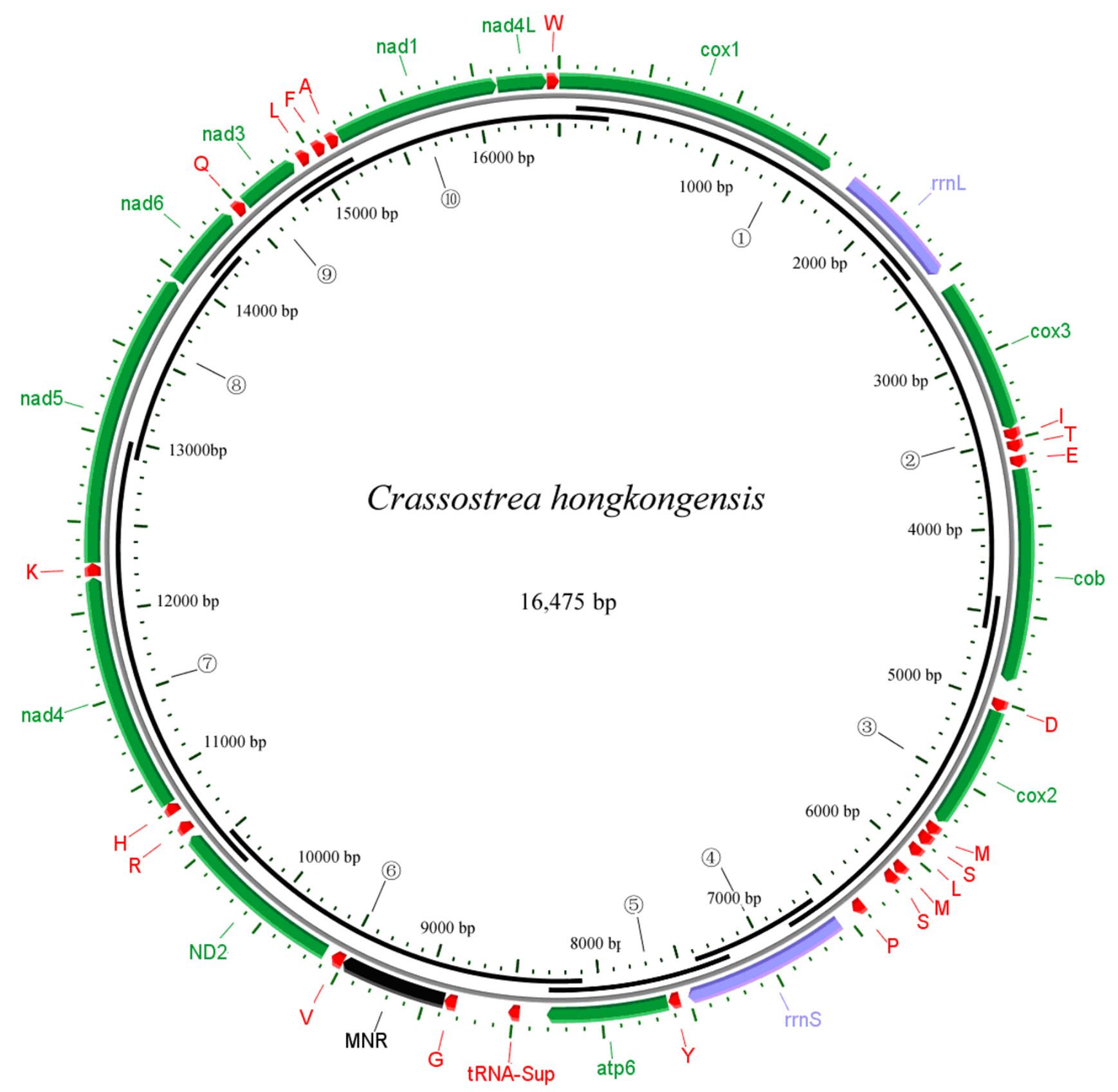

Figure I

Gene map of the mitochondrial genome of $C$. hongkongensis and assembly indication of the ten overlapping large fragments (1) (10) through PCR amplification.

virginica, the genome length difference between them (1749 bp) is greater than that between C. gigas and C. virginica (982 bp). Similarly, the lack of duplicated $r r n S$ in $C$. virginica in this segment may account for the length difference between C. gigas and the C. virginica. As observed by Rawlings et al. in Dendropoma, this kind of variation in gene order within a genus is likely to be associated with "hot spots" of rearrangements, and may be explained by an intra-mt recombination model [13].

Although gene overlap is common in animal mt genomes, there are only two such genes in C. hongkongensis $\mathrm{mt}$ genome, nad4 overlaps with trn $H$ by 1 nucleotide (Table 1 ), while in C. gigas and C. virginica there are no overlap- 


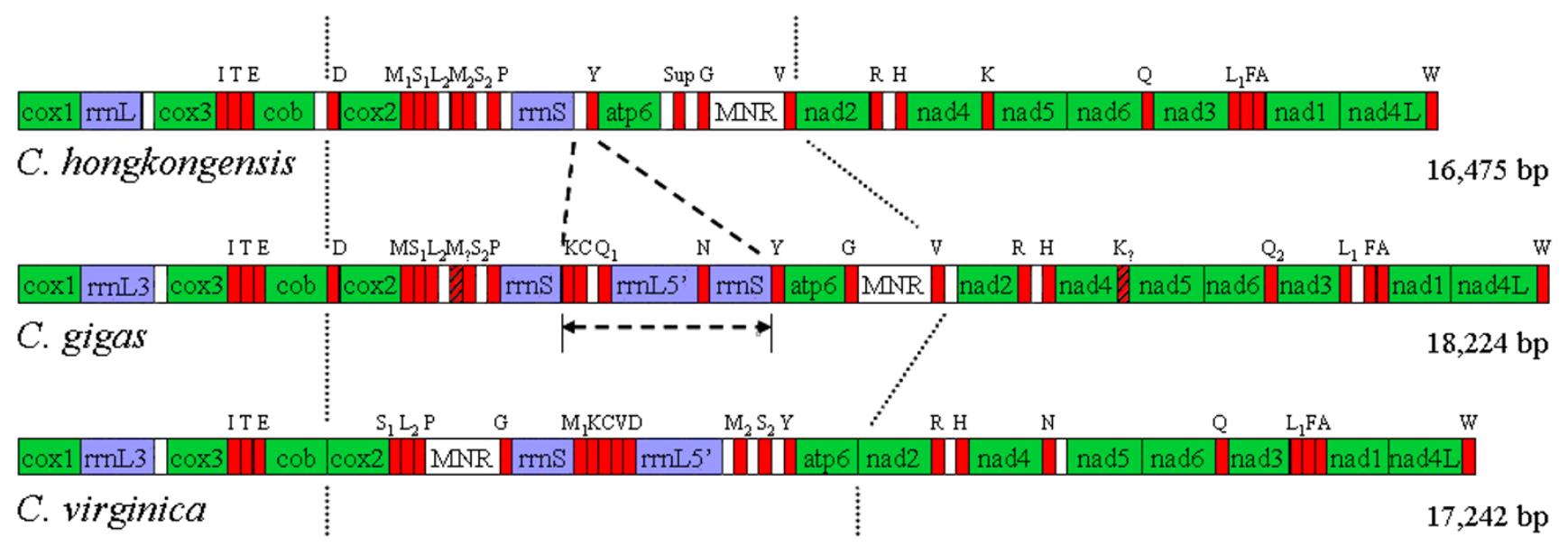

\section{Figure 2}

Mitochondrial gene order and comparison of $\boldsymbol{C}$. hongkongensis, $\boldsymbol{C}$. gigas and $\boldsymbol{C}$. virginica. Genes are abbreviated as in the text. Noncoding regions are indicated by white boxes. Locations of trnM-like and trnK-like structure in $C$. gigas are hatched. Section between dotted lines is the region in which significant gene order rearrangements are present among the three oysters ("hot spots" of rearrangements). Segment between dash lines and arrows indicate the region present in $C$. gigas but absent in $C$. hongkongensis.

ping genes [14]. Additionally, four protein-coding genes directly abut each other as they do in C. gigas:nad5-nad6 and nad1-nad4L. In C. virginica, 8 genes abut each other: cob-cox 2 and atp6-nad2, in addition to the two pairs just mentioned [5]. As usual, no introns were found, thus it is likely that all of the genes from the coding strand are expressed as a polycistronic RNA that is then processed enzymatically to release the protein-coding genes' mRNAs, as reported in a few cases [15]. Since tRNA secondary structures play a crucial role in RNA maturation from the polycistronic transcripts, it is not clear by what mechanism transcript cleavage would occur at the 3 ' end of nad5, nad1 and cox1, as these are not flanked by tRNA genes [16].

Noncoding regions between genes totaled to 1,561 bp in length, with $608 \mathrm{bp}$ in the MNR and another $953 \mathrm{bp}$ dispersed in 29 intergenic regions (Table 1). The A+T composition of $C$. hongkongensis mt-DNA is $65.4 \%$, lower than that of many other invertebrates, but comparable to the $63.3 \% \mathrm{~A} / \mathrm{T}$ composition of C. gigas mt-DNA, as well as that of C. virginica $(61.1 \%)$ and $M$. edulis $(61.8 \%)$. This $\mathrm{A}+\mathrm{T}$ bias pattern holds for all protein-coding, tRNA, rRNA genes while noncoding nucleotides except MNR, display an even higher A+T content of $77.8 \%$, significantly higher than the $65.8 \%$ seen in C. virginica and $69.5 \%$ seen in the Pacific oyster. Strand skew measures for the distribution of base pairs show an AT skew $[(\mathrm{T}-\mathrm{A}) /(\mathrm{T}+\mathrm{A})]$ value of 0.134 and GC skew $[(G-C) /(G+C)]$ value of 0.207 , respectively, almost the same as those of $C$. gigas and very similar to those of $C$. virginica $[5,17]$. This indicates that the strand containing genes is quite rich in $\mathrm{T}$ and $\mathrm{G}$ in contrast to that of other mollusks like Graptacme eborea, in which the skew values are extremely close to zero [4]. The observed $\mathrm{G}$ and $\mathrm{T}$ richness of the gene coding strand is evidence of codon usage bias.

\section{Transfer RNA genes}

In total, 21 tRNA genes plus a putative suppressor tRNA gene were identified based on their respective anticodons. Sequences complementary to the coding strand (including that for the suppressor tRNA) can form an expected cloverleaf structure, with ranging in size from 65 to 75 nucleotides. As found in the other two Crassostrea mtsequences as well as in mtDNA of some other species (Katharina tunicata, Cepaea nemoralis, M. edulis, M. galloprovincialis, Argopecten irradians), two serine and two leucine tRNA genes are differentiated in C. hongkongensis by their anticodons (UUA for Leu1, CUA for Leu2, AGA for Ser1, UCA for Ser2). Similarly, an additional $t r n M$ with a cognate anticodon was also detected, as found in C. gigas, C. virginica, V. philippinarum and Mytilus.

The new finding in this study is that $\operatorname{trn} C$ and $t r n N$ genes are absent from the $\mathrm{mt}$ genome of $C$. hongkongensis (Fig. 2 ), a phenomenon not reported before for any other mollusk species with mitochondrial genome data available so far, including Mizuhopecten yessoensis, which only has nine identified tRNA genes, though. To confirm the absence of these genes, the mt genome of one more individual of $C$. hongkongensis was sequenced. Both tRNA genes (and duplicated or split ribosomal gene) were still found 
absent in the second individual as well. Although tRNAs play a crucial role in RNA maturation from polycistronic transcripts, the number of distinct tRNA genes present in $\mathrm{mt}$ genomes varies greatly across eukaryotes. Reportedly, the loss of a tRNA gene (trnE) was detected also in Antarctic fish and it co-occurred with the loss of nad6 gene [18]. It is predominantly thought that the loss of tRNA genes is ameliorated via import of nuclear tRNAs [19]. Comparison of gene order (including tRNA genes) between $C$. hongkongensis and C. gigas shows that the two genomes are almost identical, except for the segment between $r r n S$ (the one abutting $\operatorname{trn} P$ ) and the $\operatorname{trn} Y$ gene in C. gigas, which (the segment) is absent from C. hongkongensis (Fig. 2). This segment of C. gigas contains $r r n L ' 5$, duplicated $r r n S$, and tRNA genes $\operatorname{trn} K, \operatorname{trn} Q 1, \operatorname{trn} C$ and $\operatorname{trn} N$; all of these loci are absent in $C$. hongkongensis (thus $C$. gigas has 4 more tRNA genes than does $C$. hongkongensis). The absence of the four tRNA genes and two duplicated or split rRNA genes could be explained reasonably if we suppose that the ancestor of $C$. hongkongensis had this segment as C. gigas currently does and then it was lost through DNA rearrangement. This is very likely an example of "tandem duplication-random loss (TDRL)" mechanism for gene rearrangement. Meanwhile, since extra copies of other two tRNA gene trnK and $\operatorname{trn} Q$ are found outside this region, their loss does not lead to a complete absence of these two tRNA genes from the mitochondrial genome.

Interestingly, a putative suppressor tRNA gene was identified. This suppressor tRNA has an anticodon sequence of 3'AUU, corresponding to nucleotides $8462-8527$ of the complete DNA sequence. It therefore is a nonsense suppressor, and could recognize the stop codon UAA in the mRNA and, instead of terminating, insert an amino acid at that position in the polypeptide chain [20]. A BLAST search failed to identify any homologous sequence of the putative suppressor tRNA gene, although the tRNA has a predicted secondary structure similar to that of other tRNAs. Lastly, as seen in C. gigas, C. virginica and many other mollusk species, the Leu2 (UUA) tRNA gene contains the mitochondrial rRNA termination box, a quite conserved heptamer TGGCAGA, at nucleotides 8 to 14 [21].

\section{Protein-coding genes}

Among the supposed 13 protein-coding genes, 12 were identified in C. hongkongensis through open reading frame (ORFs) searching. No atp8 coding sequence was detected in this process. Boore [1] mentions that a lack of the atp 8 gene is one of several unusual features of the Mytilus $\mathrm{mt}$ sequence. The apt8 gene is missing from the mt-DNA of almost all bivalve species studied so far, including C. gigas, C. virginica, Mytilus, P. magellanicus, A. irradians, M. yessoensis and Acanthocardia tuberculata. The one exception found so far is Hiatella arctica in which the apt8 gene is present. Interestingly, $V$. philippinarum, originally not annotated for gene atp 8 in its $\mathrm{mt}$-genome, was recently found to contain a putative atp 8 gene, though it apparently only encodes 37 amino acids and therefore has questionable gene function [7]. In contrast, all Gastropoda species (14) studied to date possess an atp 8 gene, and as do all Cephalopoda species (11) examined up to now. Other mollusk species, from Polyplacophora K. tunicata to Scaphopoda G. eborea and Siphonodentalium lobatum, have an atp 8 gene as well.

The 12 genes in $C$. hongkongensis are similar in length to their counterparts in Crassostrea. However, C. hongkongensis and C. gigas share a higher degree of amino acid similarity in 8 genes than do C. hongkongensis or C. gigas and C. virginica. Also, a higher level of amino acid identity is shared between $C$. hongkongensis and C. gigas than that is seen between other pairs (Table 2). All protein-coding genes start with typical invertebrate initiation codons, with 8 employing ATG and the other 4 using ATA. Six protein-coding genes were terminated by a TAA and five by a TAG codon, and one by an incomplete termination codon T--, with its likely completion occurring by polyadenylation after transcript processing [15].

Amino acid identity in proteins for oyster pairs ranged from as low as $47 \%$ between $C g-C v$ in nad2 to as high as 98.7\% between $\mathrm{Ch}-\mathrm{Cg}$ in cox2. The overall level of the identity among the three Crassostrea species varied from $51.3 \%$ (nad6) to $91.7 \%$ (cox1), significantly lower than the corresponding values among three congeneric Mytilus species. Just as the gene order is less conserved than that in Mytilus species, Crassostrea species exhibit lower conservation of amino acid identity in all protein-coding genes (Table 2). Amino acid identity is also much lower than that found amongst five Drosophila species [5]. According to our data (Table 2), it appears that the most conserved protein-coding genes are cox 1 and $\operatorname{cox} 2$ (identity > 90\%), and the least conserved are nad2, nad5 and nad6 (identity $<60 \%$, Table 2) in Crassostrea.

\section{Gene order and pair analysis of genome rearrangements in Crassostrea}

It's well known that gene arrangements usually remain steady over long periods of evolutionary time (especially for protein-coding genes), in contrast to the significant variation and rapid evolution of mtDNA sequences [1]. With some exceptions, mitochondrial gene order is relatively stable within major groups, and generally variable among groups [22]. However, this appears not always to be the case in mollusks. While mt-gene rearrangements appear to be extensive in the major groups of mollusks, Rawlings et al. reported that protein-coding gene rearrangements have occurred even within a genus (e.g. in the 
Table 2: Protein-coding gene assignments and identity of the three Crassostrea species

\begin{tabular}{|c|c|c|c|c|c|c|c|c|}
\hline \multirow[b]{2}{*}{ Protein } & \multicolumn{3}{|c|}{ Number of amino acids } & \multicolumn{3}{|c|}{$\%$ identity } & \multicolumn{2}{|c|}{$\%$ identity in congeners } \\
\hline & $C h^{*}$ & $C g^{*}$ & $C v^{*}$ & $\mathrm{Ch}-\mathrm{Cg}$ & $C h-C_{v}$ & $\mathrm{Cg}-\mathrm{Clv}_{\mathrm{V}}$ & Crassostrea§ & Mytilus ${ }^{\dagger}$ \\
\hline $\operatorname{coxl}$ & 539 & 538 & 540 & 97.6 & 92.8 & 92.0 & 91.7 & 98.9 \\
\hline $\operatorname{cox} 3$ & 289 & 291 & 290 & 87.8 & 63.3 & 64.0 & 61.9 & 83.0 \\
\hline$c o b$ & 401 & 412 & 403 & 85.5 & 71.3 & 71.8 & 68.5 & 84.6 \\
\hline $\operatorname{cox} 2$ & 233 & 233 & 230 & 98.7 & 91.0 & 91.0 & 90.6 & 97.5 \\
\hline atp6 & 227 & 227 & 224 & 96.9 & 70.2 & 70.6 & 69.7 & 97.5 \\
\hline nad2 & 332 & 332 & 331 & 87.7 & 49.1 & 47.0 & 57.5 & 89.9 \\
\hline nad4 & 450 & 450 & 449 & 81.4 & 71.2 & 67.8 & 63.9 & 92.0 \\
\hline nad5 & 556 & 556 & 555 & 79.2 & 62.9 & 60.0 & 56.6 & 91.4 \\
\hline nad6 & 157 & 158 & 153 & 77.2 & 57.6 & 54.4 & 51.3 & 66.5 \\
\hline nad3 & 116 & 116 & 117 & 87.1 & 67.5 & 61.5 & 60.7 & 95.7 \\
\hline nadl & 311 & 311 & 311 & 87.8 & 73.6 & 70.7 & 69.1 & 96.7 \\
\hline $\operatorname{nad} 4 L$ & 93 & 94 & 93 & 91.5 & 74.2 & 68.1 & 67.0 & 98.9 \\
\hline
\end{tabular}

${ }^{*}$ Ch: Crassostrea hongkongensis, $C g$ : $C$. gigas, $C v$ : $C$. virginica; $\S$ refer to the identity among the 3 Crassostrea species: $C$. hongkongensis, $C$. gigas and $C$. virginica; † refer to the identity among the 3 Mytilus species: $M$. edulis, M. trossulus and M. galloprovincialis.

vermetid gastropod Dendropoma), indicating that dramatic changes could also take place at the level of finescale phylogeny [13]. Several possible mechanisms have been proposed to explain gene rearrangements in $\mathrm{mt}$ genomes, including TDRL and "intra-mt recombination" models. TDRL is believed to occur primarily in vertebrates, but it is likely to occur in mollusks as well, as exemplified putatively by the occurrence of the duplicated gene block cox1-cox2-atp8-atp6 and cox3 as an intermediate state in this process for Dosidicus gigas and Todarodes pacificus in Cephalopoda, and also by the absence of the segment of tRNAs-duplicated rRNA genes found in this study as a consequence in the proceeding for $C$. hongkongensis $[23,24]$. Furthermore, the occurrence and subsequent differentiation of duplicated tRNA genes and rRNA genes in some species (such as C. gigas and C. virginica) may be another consequence following this rearrangement. Since this model cannot explain rearrangements in which a gene moves from one strand to the other, intra-mt recombination is thought to account for both these rearrangements as well as gene loss. Theoretically, when two proximate double-stranded breaks occur and the DNA circularizes to form mini-circles, segment loss often occurs; if the circular piece is re-inserted into the genome, inversion (reversal) is easily produced $[25,26]$. These seem to occur frequently in mollusks across groups and species.

According to available data, bivalves apparently have significantly great amount of mt gene rearrangement, with gene translocation across all gene classes and very few shared gene boundaries. On the other hand, loss of protein-coding genes is also a common phenomenon, as mentioned above. It is known that some mt protein-coding genes were gradually lost, functionally and then physically, over long evolutionary periods of time. Physical loss of the atp 8 gene, for example, was first detected in nematodes, and then in Mytilus, Crassostrea, M. yessoensis and male mitotype of $V$. philippinarum, although a remnant of its ancestral gene was detected in $C$. virginica $[3,5,27-29]$. Functional loss of atp 8 was revealed in female mitotype of $V$. philippinarum. In Antarctic fish, even the nad6 gene was also lost [18]. Based on the situation mentioned above, it could be possible, as more data become available, to find additional bivalve species lacking atp 8 or other genes, provided these genes are replaced by functional gene transfer to the nucleus [30].

Genome rearrangement studies are based on genomewide analysis of gene orders. The variation of $\mathrm{mt}$ gene order occurred in Cassostrea were examined closely through pair analysis of genome rearrangements and direct comparison. It is shown that there are at least five permutations between C. gigas and C. virginica (Fig. 3): indel of $\operatorname{trnQ1}, \operatorname{trnK}$ and duplicated rrnS; transposition of $\operatorname{trn} N$; transpositions of trnG, trnV andMNR; transpositions of trnK1, trnC, rrnS and MNR; and transpositions of trnD, trnM1, trnM2 and trnS2. However, only one single permutation is inferred between $C$. gigas and C. hongkongensis, involving the indel of four tRNA genes (trnK1, trnC, trnQ1 and $\operatorname{trnN}$ ) and two duplicated or split rRNA genes (rrnL5' and rrnS), obviously. With three Cassostrea mtDNA genomes, it was supposed to be able to find ancestral genome scenario. However, the distinct feature (absence of a DNA region) of $C$. hongkongensis mtDNA genome prevented the analysis of reconstructing rearrangement: only the genes that all genomes involved have in common are considered for analysis, i.e. repetitions or gaps (indels) in genomes are excluded. As gene order of $C$. hongkongensis and $C$. gigas would be the same if the indel between them is excluded, pair analysis of genome rearrangements in the three genomes would be actually conducted for two genomes (Fig. 3) and hence no ancestral genome scenario could be found for Cassostrea. Clearly, the rearrangement distance of 5 between $C$. gigas and $C$. virginica is a great 


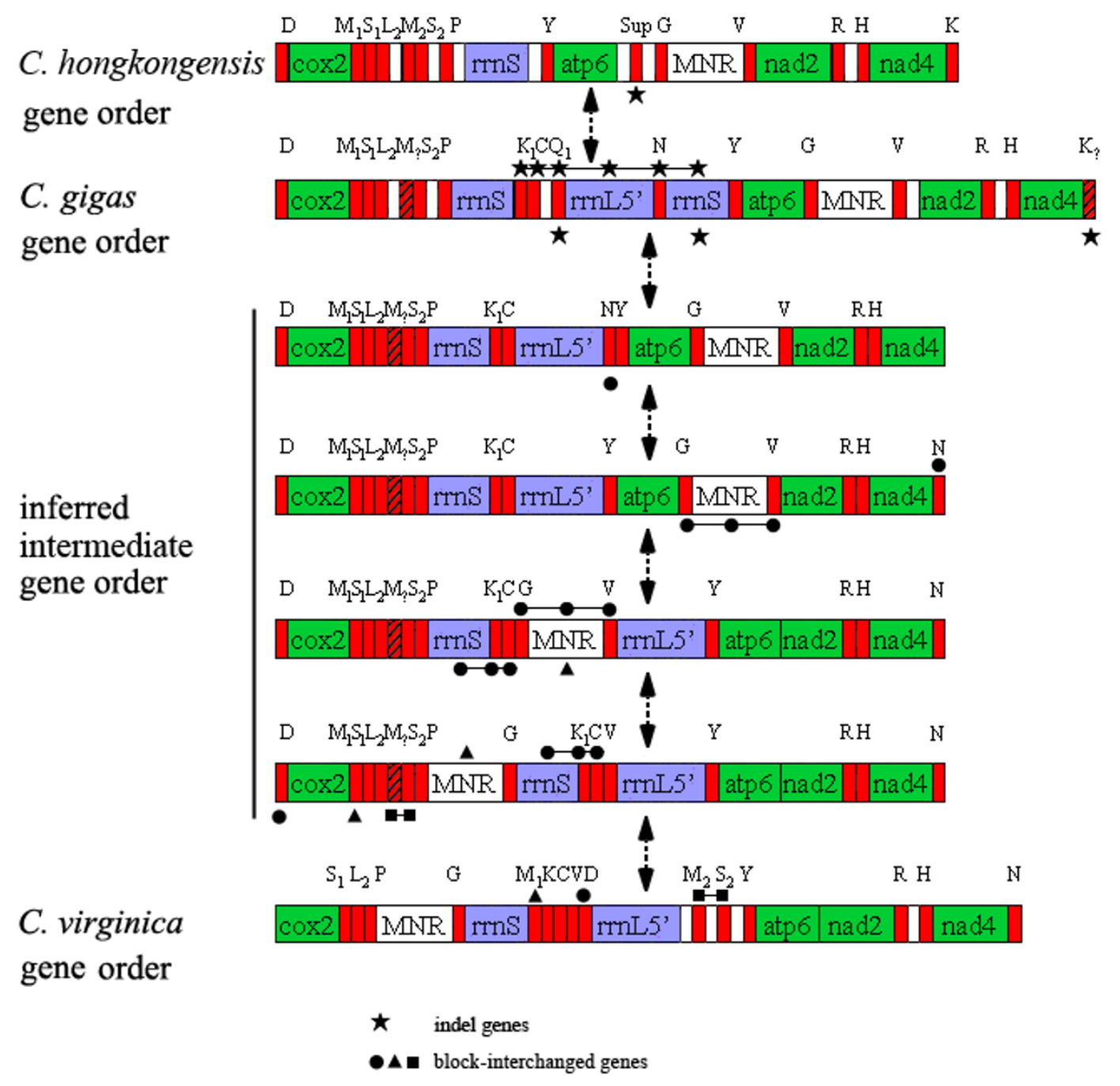

Figure 3

Pair analysis of mitochondrial genome rearrangements with SPRING (Sorting Permutation by Reversals and block-INterchanGes) in the three Crassostrea species. Star symbol denotes indel genes; dots, solid triangles and squares indicate block-interchange genes during putative genome rearrangements of Crassostrea, respectively. Symbols connected by line denote abutted genes. Double-arrows represent directions and steps in putative procedure of genome rearrangements.

value within a genus, indicating a high degree of rearrangements. Obviously, the distance between $C$. hongkongensis and $C$. gigas would normally be 1 , even without analysis.

The commonly occurred rearrangements are reversals and block-interchanges (generalized transpositions). However, the latter should be the dominant one in bivalves studied to date, because all these genomes have a single transcriptional orientation, except for L. ornata. Clearly, the absolute majority of block-interchanges must have occurred in the "hot spot" region for the 3 Cassostrea genoms (Fig. 3). That if this is true in other Cassostrea species could be verified when more mt DNA genomes become available in the future.

\section{Codon usages and codon bias}

A total of 3704 amino acids are encoded by the C. hongkongensis mitochondrial genome, compared with 3718 and 3696 for its counterpart C. gigas and C. virginica, 
respectively. Similar to these two counterparts, leucine (468) and serine (420) are the most frequently encoded amino acids, followed by valine (334) and phenylalanine (308); arginine (59) is the least frequent. Individually, UUU (Phenylalanine) is definitely the most frequently used codon not only in C. hongkongensis $(7.7 \%)$, but also in C. gigas (7.4\%) and C. virginica (5.8\%) as well, followed by AUU (Isoleucine) in the three species (5.7\%, $5.8 \%$ and $5.2 \%$, respectively).

Moreover, among 3704 codons in C. hongkongensis, 2788 (75.3\%) end in an A or T, a more pronounced percentage than that observed in the other two Crassostrea species (71.0\% and $64.7 \%$, respectively) but a phenomenon observed in the typical invertebrate codon bias. There is a strong bias against the use of $\mathrm{C}(8.6 \%)$ at the third position nucleotide in all codons. In detail, for amino acids with a fourfold degenerate third position, codon families ending with $\mathrm{T}$ are the most frequently used, except in serine 1 and arginine codons. Codons ending with A are used next most frequently. This is also the case for twofold degenerate codons. In other words, in every case where an amino acid can be specified by any NNY codon, the $C$. hongkongensis has a much higher proportion of NNT: NNC. At the second position, there is even a stronger bias in favor of the use of $\mathrm{T}(42.5 \%)$, which is also true for $C$. gigas (42.3\%), C. virginica (43.0\%) and M. edulis (43.5\%). While at the first codon position, T (30.9\%) has the highest percentage followed by G $(27.8 \%)$, so are the cases in species mentioned above (Fig. 4).

Leucine can be specified by six different codons of TTR and CTN, and the proteins of the Crassostrea species have a very similar number of leucines $(468,461$ and 472 , respectively). As the reflection of base bias in codons, $C$. hongkongensis, together with C. gigas and C. virginica, has a significantly greater percentage of leucines encoded by TTA and CTT codons (with range of 53.2-67.0\%), primarily at the expense of CTC and CTG codons. Similarly, in the case of serine with 8 different codons (TCN and AGN), a much higher proportion (with range of $60.1-65.5 \%$ ) of AT rich codons of TCT, AGA and TCA are clearly observed in Crassostrea congeners.

\section{Ribosomal RNA genes}

BLAST searches assigned locations of the $12 \mathrm{~S}$ and $16 \mathrm{~S}$ rRNA genes in the C. hongkongensis mt-genome. The $12 \mathrm{~S}$ rDNA is contained in a 948 bp region (6558-7505) flanked by $\operatorname{trn} P$ and $\operatorname{trn} Y$, and as seen in C. virginica, but in contrast to C. gigas, no duplicated small subunit rRNA gene was detected. Alignment of the 12S rDNA from the three oysters shows that there is a fairly homologous core of 979 nucleotides at $78.3 \%$ identity (with 37 nucleotide indels and 175 substitutions), corresponding to 65587505 for C. hongkongensis, 3855-4800 and 5931-6879 (duplicated) for C. gigas, and 6847-7797 for C. virginica, respectively. However, if only $C$. hongkongensis and $C$. gigas are considered, the homologous core is 949 nucleotides long with $96.7 \%$ identity, with two indels and 29 substitutions, corresponding to 6558-7505, and 38554800 and 5931-6879 (duplicated) in the genomes, respectively.

The 16S rRNA gene is 712 bp long, flanked by proteincoding genes cox 1 and cox3. Unlike the 16S rRNA gene in C. gigas and C. virginica mt-DNA, it is not split or duplicated into two fragments (Fig. 2) [5]. The 16S rRNA gene of $C$. hongkongensis and $r r n L 3$ ' half of $C$. gigas shows nucleotide identity of $95.8 \%$ over 715 aligned bases (including 3 indels and 27 substitutions), while it is $82.4 \%$ between C. hongkongensis and C. virginica over 721 nucleotide alignment (including 11 indels and 116 substitutions). Unlike the high identity of $r r n S$ among three Crassostrea (including the duplicated one in C. gigas), there is low identity between $r r n L 3$ and $r r n L 5$ (36.4\%) in C. gigas, perhaps a consequence of $r r n L$ 's modest evolutionary fragmentation, rather than duplication [31].

\section{Noncoding regions}

As in other two oysters and Mytilus, the C. hongkongensis $\mathrm{mt}$ genome includes a large number of noncoding nucleotides, in contrast to G. eborea. Excluding the 3'UTR sequences for protein-coding genes, there exist large intergenic segments in $C$. hongkongensis and 10 of which were larger than $50 \mathrm{bp}$ in length. Among these regions, a 608 nucleotide segment between $\operatorname{trn} G$ and $\operatorname{trn} V$ was putatively identified as the major noncoding region (MNR; Table 1 , Fig. 1 and 2), on the basis of its noncoding characteristics and $\mathrm{A}+\mathrm{T}$ richness $(77.8 \%)$, a feature typically used for identification of the mitochondrial control region and thought to contain replication origin [1]. Additionally, several $(A)_{n}$ and $(T)_{n}$ homopolymer tracts were contained in this region. The second largest intergenic sequence was a fragment between suppressor tRNA gene and $\operatorname{trn} G$, with a length of $294 \mathrm{bp}$ and $\mathrm{A}+\mathrm{T}$ content of $70.8 \%$. Alignment of MNR between C. hongkongensis and C. gigas detected a fragment of 60 bp long, with $90.0 \%$ sequence identity and $\mathrm{A}+\mathrm{T}$ content of $83.3 \%$ and $80.0 \%$, respectively, or a sequence of $51 \mathrm{bp}$ in length, with $96.1 \%$ identity, A+T content of $80.4 \%$ and $82.4 \%$, respectively.

\section{Conclusion}

Although the arrangement of protein-coding genes of $C$. hongkongensis's $\mathrm{mt}$ genome is identical with that of $C$. gigas and C. virginica, and a moderate to high level of gene/ amino acid identity is shared among the three Crassostrea species, $C$. hongkongensis exhibits a high degree of variation in gene order and gene content. The most striking of these are the absence of the two tRNA gene $\operatorname{trnC}$ and $\operatorname{trnN}$ and duplicated or split rRNA genes. Based on a compara- 

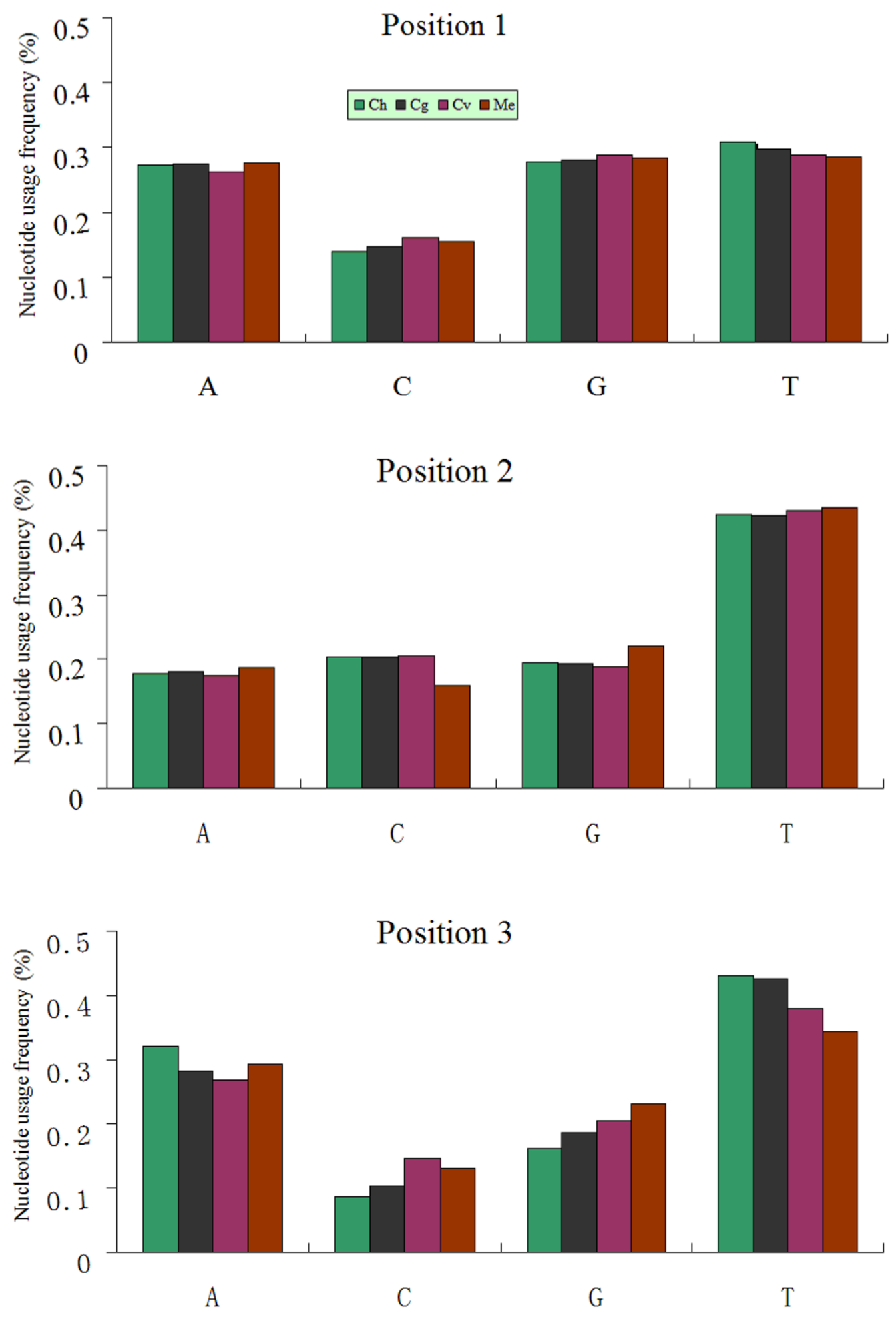

Figure 4

Nucleotide usage frequency of three Crassostrea species with Mytilus edulis as a reference. Ch: Crassostrea hongkongensis, Cg: C. gigas, Cv: C. virginica and Me: M. edulis. 
tive analysis, we assume that the absence of these genes is the result of evolutionarily loss of a genomic segment that was present in the ancestor of Crassostrea, and a likely case of "Tandem duplication-random loss" for genome rearrangement. While this novel and interesting feature of $C$. hongkongensis and the comparison of mt-genomes among the three Crassostrea species presented here have yielded useful insights into possible mechanisms underlying variation of gene order and gene content change for Crassostrea, more information could be expected from mt-genome studies of other oysters in Ostridae, promising intensive understanding of gene order/content change, as well as tRNA mutation and genome evolution for oysters and other bivalves.

\section{Methods \\ $P C R$ and sequencing}

Adductor muscle from a C. hongkongensis individual collected in Beihai, Guangxi province, China was used for this study. Total genomic DNA was extracted using a standard phenol/chloroform method [32]. Based on alignment and comparison of complete mitochondrial genome sequences of $C$. gigas and C. virginica, ten genusspecific primer pairs were designed for amplifications of mtDNA large fragments in C. hongkongensis (Table 3), and then the complete mitochondrial genome was amplified in 10 overlapping large fragments accordingly (Fig. 1). PCR was performed in $25-\mu$ l reaction volume, containing $2.0 \mathrm{mM} \mathrm{MgCl} 2,0.2 \mathrm{mM}$ dNTP, $0.5 \mu \mathrm{M}$ of each primer, 1.0 $\mathrm{U}$ Taq polymerase, $1 \times$ PCR buffer and $1 \mu \mathrm{l}$ template DNA. PCR cycling condition were $94^{\circ} \mathrm{C}$ for $2 \mathrm{~min}$; then 35 cycles of $94^{\circ}$ for $1 \mathrm{~min}$, annealing temperature for $1 \mathrm{~min}$ and $72^{\circ} \mathrm{C}$ for $1.5 \mathrm{~min}$; with a final step of $72^{\circ} \mathrm{C}$ for $5 \mathrm{~min}$. PCR products were checked by electrophoresis on $1 \%$ agarose gel and purified using Qiagen PCR Purification kits (Qiagen, USA). Purified products were then used as templates directly for cycle sequencing reactions. Species-specific primers were designed and used for primer walking sequencing, which was performed for both strands of each sample on an ABI 3730 DNA sequencer (ABI, USA). When two mt tRNA genes was found absent in the individual of C. hongkongensis sampled, the genome for one more individual was then sequenced for confirmation.

\section{Sequence analysis and gene order comparison}

During the processing of large fragments and those from walking sequencing, regular and manual examinations were used to ensure reliable overlapping and correct genome assembly. Protein-coding and ribosomal RNA genes were firstly identified using BLAST searches at GenBank, and then by alignment with previously published $\mathrm{mt}$ genomes from species of Crassostrea, Mytilus and other closely related mollusks [33]. Amino acid sequences of protein-coding genes were inferred with ORF Finder using invertebrate mitochondrial genetic code [34]. Identification of tRNA genes was conducted with tRNAscan-SE using mito/chloroplast genetic code and default search mode or setting the cove cutoff score to 1 when necessary [35,36]. Potential cloverleaf structures for identified tRNAs were determined in tRNAscan-SE. Comparisons of mitochondrial gene order were conducted and facilitated with published mollusk genomes from GenBank and OGRe (the Organellar Genome Retrieval system) web site [37-39]. Pair analysis of genome rearrangements was

Table 3: Primers used for amplification of large fragments in Crassostrea. hongkongensis mitochondrial genome

\begin{tabular}{|c|c|c|c|c|}
\hline Order & Primer name & Sequence (5'-3') & Amplification conditions* & Product size (bp) \\
\hline 1 & $\begin{array}{l}\text { RCOIA } \\
\text { MtI } 33\end{array}$ & $\begin{array}{l}\text { GGTCAACAAATCATAAAGATATTGG } \\
\text { CCGGTCTGAACTCAAATCA }\end{array}$ & $35 \times\left(94^{\circ} \mathrm{C} \mathrm{I} \mathrm{min,} 57^{\circ} \mathrm{C}\right.$ for $1.5 \mathrm{~min}, 72^{\circ} \mathrm{C}$ for $\left.1.5 \mathrm{~min}\right)$ & 2325 \\
\hline 2 & $\begin{array}{l}\text { Mt89 } \\
\text { IR }\end{array}$ & $\begin{array}{l}\text { CAGTACCTGCCCAGTGCGACAT } \\
\text { GGCTTAATTACGGCTGGTGTTT }\end{array}$ & $35 \times\left(94^{\circ} \mathrm{C} \mathrm{I} \mathrm{min,} 57.5^{\circ} \mathrm{C}\right.$ for $1.5 \mathrm{~min}, 72^{\circ} \mathrm{C}$ for $\left..5 \mathrm{~min}\right)$ & 2626 \\
\hline 3 & $\begin{array}{l}\text { CYF } \\
12-B\end{array}$ & $\begin{array}{l}\text { TTAGAGTTCCGTTTCACCCG } \\
\text { CTTTCGCTGCGGTTTAGTTAGT }\end{array}$ & $35 \times\left(94^{\circ} \mathrm{C} \mathrm{I} \mathrm{min,} 47.5^{\circ} \mathrm{C}\right.$ for $1 \mathrm{~min}, 72^{\circ} \mathrm{C}$ for $\left.1.5 \mathrm{~min}\right)$ & 2448 \\
\hline 4 & $\begin{array}{l}12-\mathrm{F} \\
\mathrm{I} 2 \mathrm{~B}\end{array}$ & $\begin{array}{l}\text { GGTTCTGGTCTAATGTTCGCT } \\
\text { GTTACTCTCCCTTTACTCCC }\end{array}$ & $35 \times\left(94^{\circ} \mathrm{C} \mathrm{I} \mathrm{min,} 47^{\circ} \mathrm{C}\right.$ for $1 \mathrm{~min}, 72^{\circ} \mathrm{C}$ for $\left.1 \mathrm{~min}\right)$ & 804 \\
\hline 5 & $\begin{array}{l}\text { I2RF } \\
\text { ATP-H }\end{array}$ & $\begin{array}{l}\text { GTAGGTCAGGACGAAGTGCT } \\
\text { AGAGCACAGGTGTTGGGAGA }\end{array}$ & $35 \times\left(94^{\circ} \mathrm{C} \mathrm{I} \mathrm{min,} 49^{\circ} \mathrm{C}\right.$ for $1 \mathrm{~min}, 72^{\circ} \mathrm{C}$ for I min $)$ & 996 \\
\hline 6 & $\begin{array}{l}727 F \\
\text { DNR }\end{array}$ & $\begin{array}{l}\text { TATTCGCCCTGACACTCTTAC } \\
\text { TCCCGTATTCCAGAAGAAGCAG }\end{array}$ & $35 \times\left(94^{\circ} \mathrm{C} \mathrm{I} \mathrm{min,} 77.5^{\circ} \mathrm{C}\right.$ for $1 \mathrm{~min}, 72^{\circ} \mathrm{C}$ for $\left.1.5 \mathrm{~min}\right)$ & 2444 \\
\hline 7 & $\begin{array}{l}\text { ND2F } \\
5 N R\end{array}$ & $\begin{array}{l}\text { AGATTTGCTGGTTTTCCTCCG } \\
\text { CTGATGTTGTAAGTCCCGCAC }\end{array}$ & $35 \times\left(94^{\circ} \mathrm{C} I \mathrm{~min}, 49.5^{\circ} \mathrm{C}\right.$ for $1 \mathrm{~min}, 72^{\circ} \mathrm{C}$ for $\left.1.5 \mathrm{~min}\right)$ & 2641 \\
\hline 8 & $\begin{array}{l}\text { ND6F2 } \\
\text { NDR }\end{array}$ & $\begin{array}{l}\text { GCTCCTACTCCTGTCTCATC } \\
\text { TGACGCTTGCGAATAAGACAC }\end{array}$ & $35 \times\left(94^{\circ} \mathrm{C} \mathrm{I} \mathrm{min,} 49^{\circ} \mathrm{C}\right.$ for $1 \mathrm{~min}, 72^{\circ} \mathrm{C}$ for $\left.1 \mathrm{~min}\right)$ & 948 \\
\hline 9 & $\begin{array}{l}\text { ND5F } \\
\text { RND }\end{array}$ & $\begin{array}{l}\text { GAGGATTTACTGCGGTGATTGG } \\
\text { GTCAGAGCCATTCCGACTATC }\end{array}$ & $35 \times\left(94^{\circ} \mathrm{C} I \mathrm{~min}, 47.5^{\circ} \mathrm{C}\right.$ for $1 \mathrm{~min}, 72^{\circ} \mathrm{C}$ for $\left.1.5 \mathrm{~min}\right)$ & 1373 \\
\hline 10 & $\begin{array}{l}\text { FLeu } \\
\text { NOI }\end{array}$ & $\begin{array}{l}\text { GCCAGGTTAGTGTGGTATTTAG } \\
\text { GAGTAAGTGGATAAGGGTGGA }\end{array}$ & $35 \times\left(94^{\circ} \mathrm{C} I \mathrm{~min}, 47.5^{\circ} \mathrm{C}\right.$ for $1 \mathrm{~min}, 72^{\circ} \mathrm{C}$ for $\left.1.5 \mathrm{~min}\right)$ & 2017 \\
\hline
\end{tabular}

* Steps of initial $94^{\circ} \mathrm{C}$ for 2 min at the beginning and final $72^{\circ} \mathrm{C}$ for 5 min after 35 cycles are omitted in cycling profile of each primer pair in the table. 
Table 4: List of taxa used for genome comparison

\begin{tabular}{|c|c|c|c|}
\hline Taxon and Species & Accession No & Taxon and Species & Accession No \\
\hline Bivalvia & & Venerupis philippinarum & NC 003354 \\
\hline Acanthocardia tuberculata & NC 008452 & Gastropoda & \\
\hline Argopecten irradians & EU023915 & Biomphalaria glabrata & NC 005439 \\
\hline Crassostrea gigas & NC 001276 & Cepaea nemoralis & $\overline{N C 001816}$ \\
\hline Crassostrea virginica & AY 905542 & Cephalopoda & \\
\hline Crassostrea hongkongensis & EU266073 & Dosidicus gigas & NC 009734 \\
\hline Hiatella arctica & NC 00845 I & Todarodes pacificus & NC 006354 \\
\hline Lampsilis ornate & $\mathrm{AY} 365193$ & Polyplacophora & \\
\hline Mizuhopecten yessoensis & NC 009081 & Katharina tunicate & NC 001636 \\
\hline Mytilus edulis & AY484747 & Scaphopoda & \\
\hline Mytilus galloprovincialis & NC 006886 & Graptacme eborea & NC 006162 \\
\hline Mytilus trossulus & NC 007687 & Siphonodentalium lobatum & NC 005840 \\
\hline Placopecten magellanicus & NC 007234 & & \\
\hline
\end{tabular}

made with SPRING (Sorting Permutation by Reversals and block-INterchanGes) [40,41]. GenBank accession numbers of mt genomes from the taxa used in this study were listed in Table 4. Gene map of the mitochondrial genome of $C$. hongkongensis was generated using CGView [42].

\section{Authors' contributions}

$\mathrm{ZY}$ designed the research and performed most of the data analyses; he also conducted examination of initial annotation and re-annotation, drafted and finalized the manuscript. ZW carried out most of the experiments (including PCR, sequence check and assembly) and initial annotation; XK initiated, led the research, and supervised all laboratory work; WS participated in data analyses and made all figures.

\section{Acknowledgements}

This work was financially supported by Natural Science Foundation of China (No. 30570242), 863 Program from Ministry of Sciences and Technology of China (No. 2006AAIOA409) and the CAS/SAFEA International Partnership Program for Creative Research Teams. The authors thank Prof. Beth De Stasio for her English review and Dr. Jianjun Xia for his sample supply and identification.

\section{References}

I. Boore JL: Animal mitochondrial genomes. Nucleic Acids Res 1999, 27: 1767-1780.

2. Helfenbein KG, Brown WM, Boore JL: The complete mitochondrial genome of the articulate brachiopod Terebratalia transversa. Mol Biol Evol 200I, 18:1734-1744.

3. Serb JM, Lydeard C: Complete mtDNA sequence of the North American freshwater mussel, Lampsilis ornata (Unionidae): An eximination of the evolution and phylogenetic utility of mitochondrial genome organization in Bivalvia (Mollusca). Mol Biol Evol 2003, 20: 1854-1866.

4. Boore JL, Medina M, Rosenberg LA: Complete sequences of the highly rearranged molluscan mitochondrial genomes of the scaphopod Graptacme eborea and the bivalve Mytilus edulis. Mol Biol Evol 2004, 2 I: | 1492-1503.

5. Milbury CA, Gaffney PM: Complete mitochondrial DNA sequence of the eastern oyster Crassostrea virginica. Mar Biotechnol 2005, 7:697-7I2.
6. Maynard BT, Kerr LJ, McKiernan JM, Jansen ES, Hanna PJ: Mitochondrial DNA sequence and gene organization in the Australia blacklip abalone Haliotis rubra (Leach). Mar Bioltechnol 2005, 7:645-658.

7. Dreyer H, Steiner G: The complete sequence and gene organization of the mitochondrial genomes of the heterodont bivalves Acanthocardia tuberculata and Hiatella arctica-and the first record for a putative Atpase subunit 8 gene in marine bivalves. Front Zool 2006, 3:13.

8. Boore JL, Brown WM: Big trees from little genome: Mitochondrial gene order as a phylogenetic tool. Curr Opin Gent Dev 1998, 8:668-674.

9. Lam K, Morton B: Mitochondrial DNA and morphological identification of a new species of Crassostrea (Bivalvia: Ostreidae) cultured for centuries in the Pearl River Delta, Hong Kong, China. Aquaculture 2003, 228: I-13.

10. Li G, Hu Y, Qing N: Population gene pools of big size cultured oysters (Crassostrea) along the Guangdong and Fujian coast of China. In Proceedings of Marine Biology of South China Sea Guangzhou, China Ocean Press; 1988:51-70.

II. Su T, Jiang S, Zhou F, Zhu C, Chen P: Mitochondrial I6S rRNA gene fragment sequence analysis in populations of Crassostrea rivularis. High Technol Lett 2005, 15(2): 100-103.

12. Xue $M, D u X$, Huang $R$, Wang $Q$ : Biochemical genetic variation in Chinese oyster Ostea rivularis. J Zhanjiang Ocean Univ 2006, 26(3):3-7.

13. Rawlings T, Collins T, Bieler R: A major mitochondrial gene rearrangement among closely related species. Mol Biol Evol 200I, 18:1604-1609.

14. Yamazaki N, Ueshima R, Terrett JA, Yokobori SI, Kaifu M, Segawa R, Kobayashi T, Numachi KI, Ueda T, Nishikawa K, Watanabe K, Thomas $\mathrm{RH}$ : Evolution of pulmonate gastropod mitochondrial genomes: comparisons of gene organizations of Euhadra, Cepaea and Albinaria and implications of unusual tRNA secondary structure. Genetics 1997, I45:749-758.

15. Fernández-Silva P, Enriquez JA, Montoya J: Replication and transcription of mammalian mitochondrial DNA. Exp Physiol 2003, 88:4I-56.

16. Ojala D, Montoya J, Attardi J: tRNA punctuation model of RNA processing in human mitochondria. Nature 1981, 290:470-474.

17. Perna NT, Kocher TD: Patterns of nucleotide composition at fourfold degenerate sites of animal mitochondrial genomes. J Mol Evol 1995, 41:353-358.

18. Papetti C, Liò P, Rüber L, Patarnello T, Zardoya R: Antarctic fish mitochondrial genomes lack ND6 gene. J Mol Evol 2007, 65:519-528.

19. Gray MW, Lang BF, Cedergren R, Golding GB, Lemieux C, Sankoff D, Turmel M, Brossard N, Delage E, Littlejohn TG, Plante I, Rioux $P$, Saint-Louis D, Zhu Y, Burger G: Genome structure and gene content in protist mitochondrial DNAs. Nucleic Acids Res 1998, 26:865-878 
20. Engelberg-Kulka H, Schoulaker-Schwarz R: Suppression of termination codons. In Escherichia coli and Salmonella: Cellular and molecular biology 2 nd edition. Edited by: Neidhardt F. Washington, DC, ASM Press; 1996:909-921.

21. Valverde JR, Marco R, Garesse R: A conserved heptamer motif for ribosomal RNA transcription termination in animal mitochondria. Proc Natl Acad Sci USA 1994, 9 I:5368-537I.

22. Boore JL, Brown WM: The complete DNA sequence of the mitochondrial genome of the black chiton Katharina tunicata. Genetics 1994, 138:423-443.

23. Moritz C, Dowling TE, Brown WM: Evolution of animal mitochondrial DNA: Relevance for population biology and systematics. Annu Rev Ecol Syst 1987, I 8:269-292.

24. Macey JR, Larson A, Ananjeva NB, Fang Z, Papenfuss TJ: Two novel gene orders and the role of light-strand replication in rearrangement of the vertebrate mitochondrial genome. Mol Biol Evol 1997, 14:91-104.

25. Lunt DH, Hyman BC: Animal mitochondrial DNA recombination. Nature 1997, 387:247.

26. Dowton M, Castro LR, Campbell SL, Bargon SD, Austin AD: Frequent mitochondrial gene rearrangements at the Hymenopteran nad3-nad5 junction. J Mol Evol 2003, 56:5I 7-526.

27. Okimoto R, Macfarlane JL, Clary DO, Wolstenholme DR: The mitochondrial genomes of two nematodes, Caenorhabditis elegans and Ascaris suum. Genetics 1992, I30:47I-498.

28. Hoffman RJ, Boore JL, Brown WM: A novel mitochondrial genome organization for the blue mussel, Mytilus edulis. Genetics 1992, I3 1:397-4I2.

29. Kim SH, Je EY, Park DW: Crassostrea gigas mitochondrial DNA. 1999. GenBank accession number AFI 77226

30. Adams KL, Palmer JD: Evolution of mitochondrial gene content: gene loss and transfer to the nucleus. Mol Phylogenet Evol 2003, 29:380-395

31. Gary MW, Schnare MN: Evolution of rRNA gene organization. In Ribosomal RNA: Structure, Evolution, Processing, and Function in Protein Biosynthesis Edited by: Zimmermann RA, Dahlberg AE. Boca Raton, FL, CRC Press; 1996:49-69.

32. Sambrook JE, Fritsch EF, Maniatis T: Molecular Cloning, A laboratory Manual. In Cold Spring Harbor 2nd edition. New York, Cold Spring Harbor Laboratory; 1989.

33. The Basic Local Alignment Search Tool (BLAST) [http:// www.ncbi.nlm.nih.gov/BLAST/]

34. NCBI Open Reading Frame Finder [http:/l www.ncbi.nlm.nih.gov/gorf/gorf.html]

35. Lowe TM, Eddy SR: A program for improved detection of transfer RNA genes in genomic sequence. Nucl Acids Res 1997, 25:955-964.

36. tRNAscan-SE Search Server [http://selab.janelia.org/tRNAscan$\underline{\mathrm{SE} /}]$

37. GenBank [http://www.ncbi.nlm.nih.gov/]

38. Jameson D, Gibson AP, Hudelot C, Higgs PG: OGRe: a relational database for comparative analysis of mitochondrial genomes. Nucl Acids Res 2003, 31:202-206.

39. OGRe (the Organellar Genome Retrieval system) [http:// drake.physics.mcmaster.ca/ogre/index.shtml]

40. Lin YC, Lu CL, Liu YC, Tang CY: SPRING: a tool for the analysis of genome rearrangement using reversals and block-Interchanges. Nucl Acids Res 2006:W696-W699.

4I. SPRING: Sorting Permutation by Reversals and block-Interchanges [http://algorithm.cs.nthu.edu.tw/tools/SPRING/]

42. Stothard $P$, Wishart DS: Circular genome visualization and exploration using CGView. Bioinformatics 2005, 2 I:537-539.

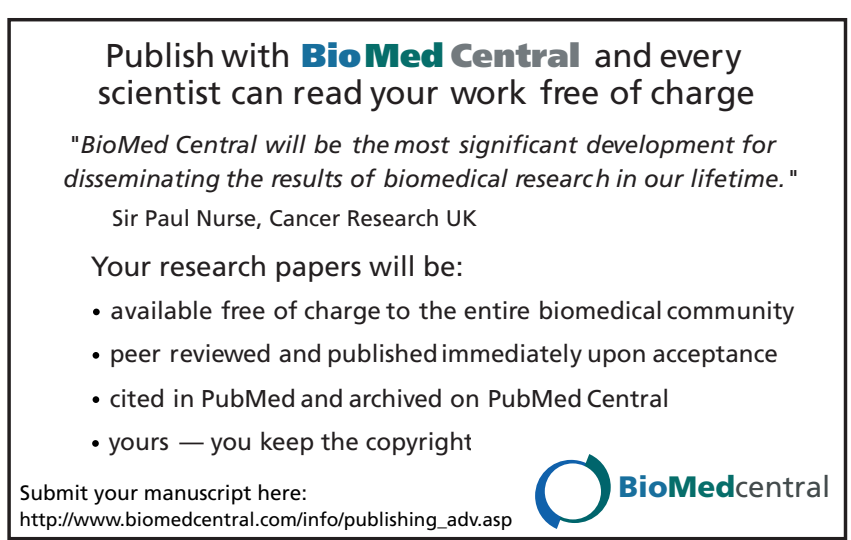

